\section{CASA TIBURCIO}

María del Carmen Nombela Nombela

José Félix Ocaña López

Laura Segarra Cañamares

Daniel Vázquez Molini

Sebastián Villar Rosales

La obra a ejecutar consiste en la rehabilitación de la denominada Casa Tiburcio, enclavada en la plaza de Búbal en Huesca.

El proceso de rehabilitación tiene por objeto acondicionar el edificio para su utilización posterior como museo, aulas y teatro al aire libre, dentro del Plan de Recuperación de que es objeto el pueblo, para así paliar los efectos de abandono tras la expropiación de tierras a sus habitantes y posterior construcción del embalse.
(1)

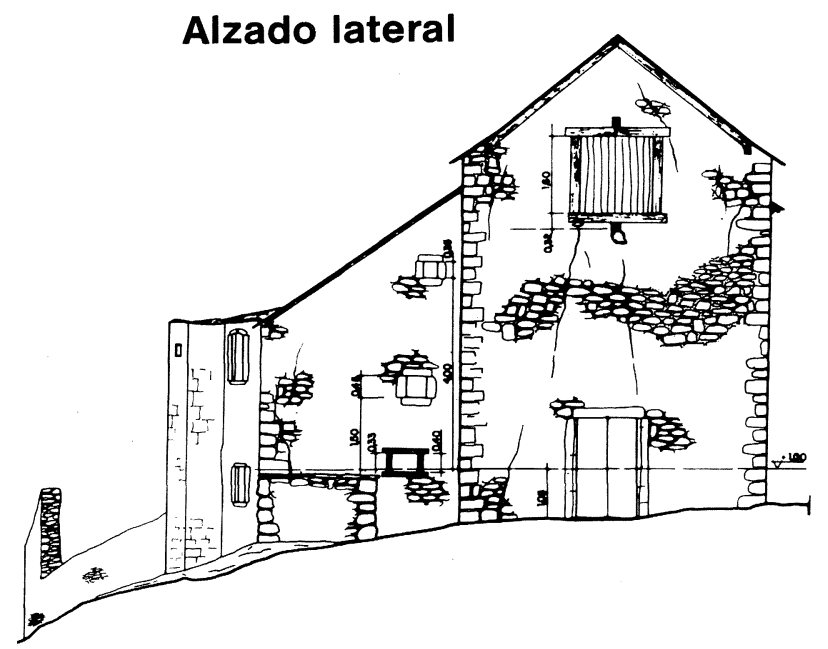

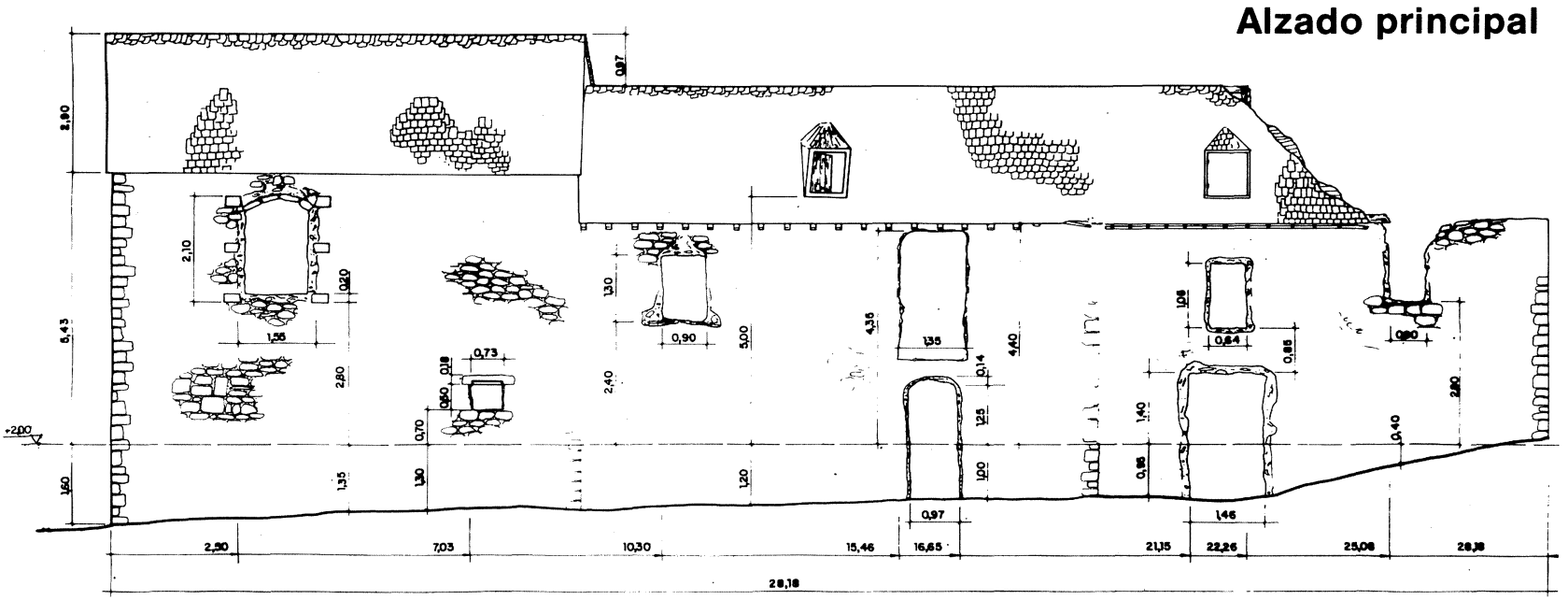

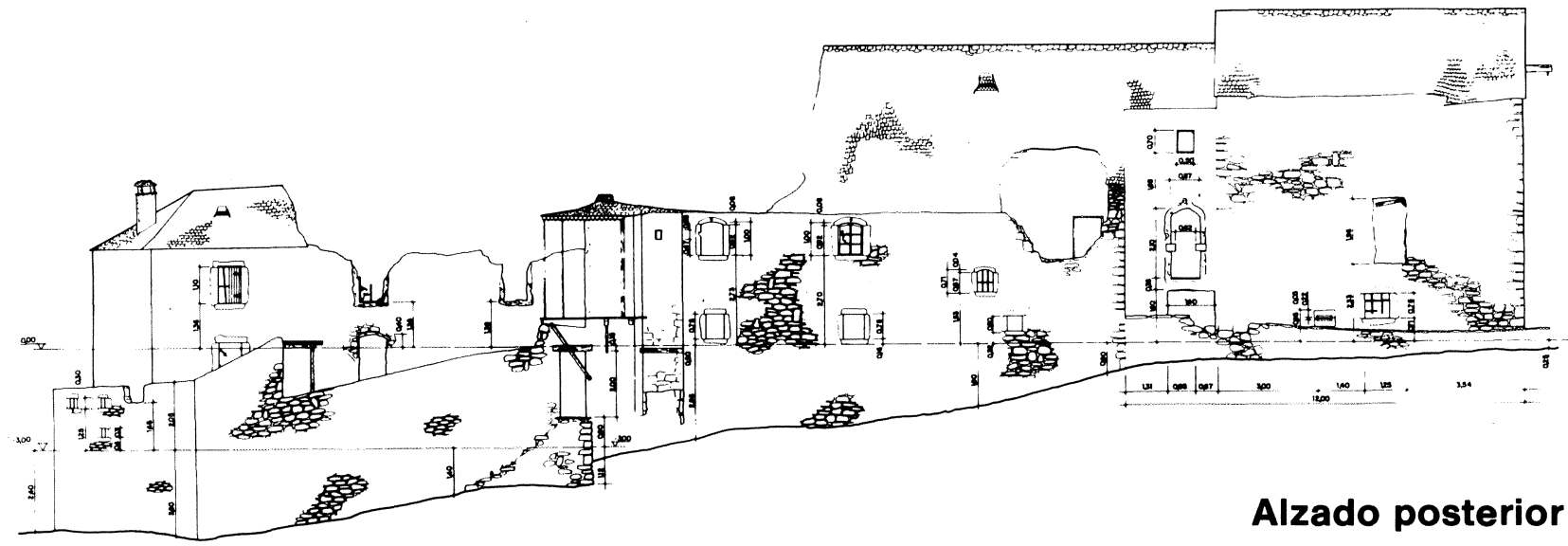



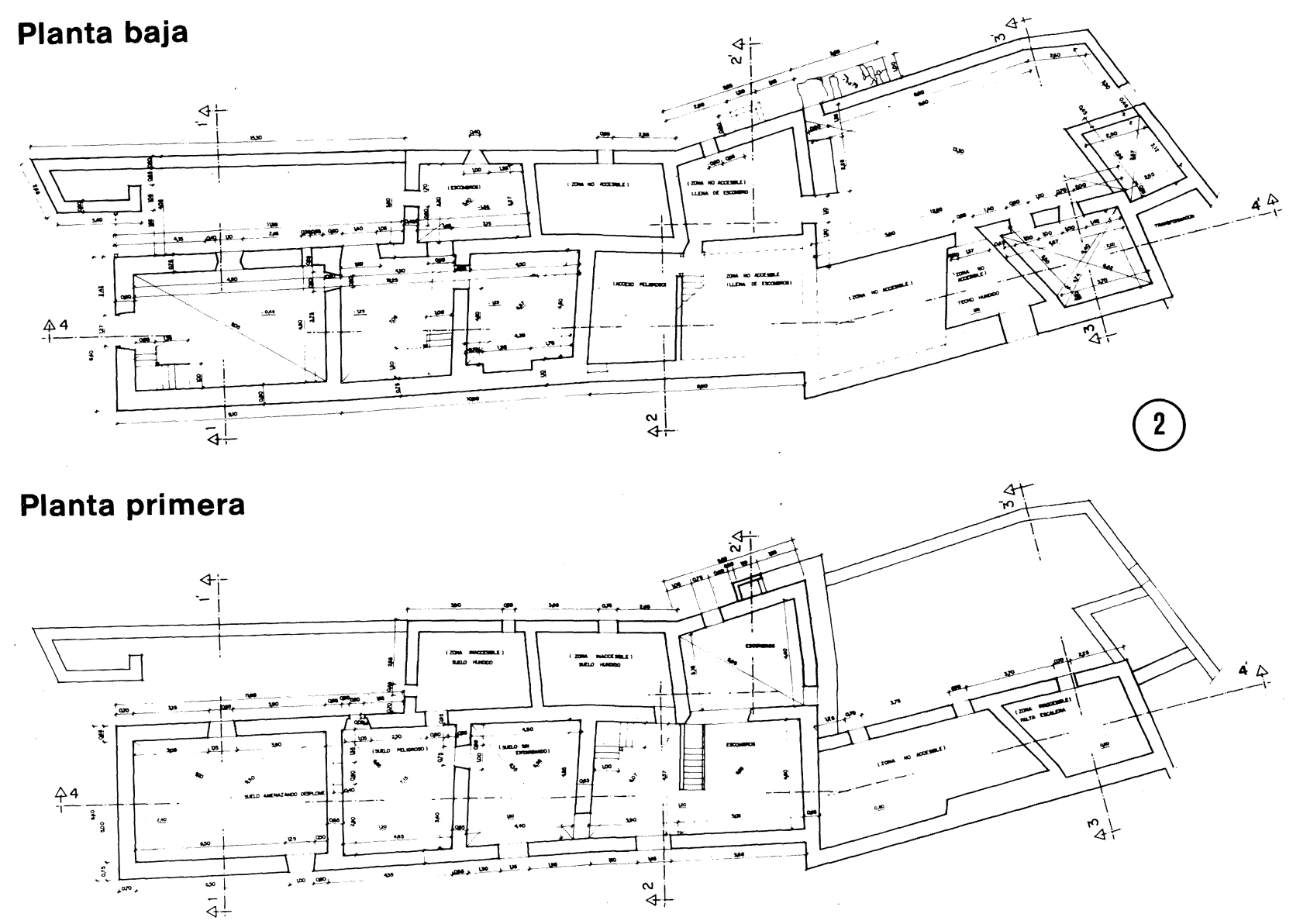

El estado del edificio es semejante al del resto de las casas del pueblo, y viene caracterizado por los siguientes aspectos:

- El exterior denota el expolio generalizado a que se vio sometido el pueblo tras su abandono, faltando en sus fachadas gran número de jambas, dinteles, etc.

- En el interior y como consecuencia de la falta de cuidados de sus cubiertas, ayudado por el clima riguroso de la zona, el grado de humedad es importante, las goteras facilitan la pudrición de la madera y así las escaleras se encuentran en avanzado estado de ruina; el entarimado, si es que existe, se encuentra en muy mal estado, resultando peligroso andar por él y si no existe queda a la vista el mal estado de las viguetas de piso.

- En muchas habitaciones el acceso resulta imposible a consecuencia de la acumulación de escombros.

Ante esta situación, se imponian árduas las tareas de medición, siendo necesario un número importante de medidas y de comprobaciones hasta conseguir el levantamiento definitivo de plantas, alzados y secciones.

El edificio destinado a vivienda, consta de dos cuerpos que quedan adosados entre sí, morfologia que se va a mantener tras la rehabilitación. En ambos cuerpos existen tres plantas: baja, primera y alta, con cuatro posibles accesos, tres a planta baja y uno a planta primera.
La cimentación existente, consistente en la prolongación de sus muros de fachada, se va a considerar suficiente, basándonos en el hecho de la presencia a poca profundidad de roca viva de gran dureza y a no haberse detectado entre los problemas patológicos de las casas ya rehabilitadas ninguno relativo a la patología de las cimentaciones. No obstante, y como queda reflejado en el plano n. ${ }^{\circ}$ 3 , no nos fue posible determinar la cota exacta de cimentación.

Como ya se ha dicho la rehabilitación del edificio pretende su utilización como museo, aulas y teatro, y en la medida de lo posible y dados los usos, se ha tratado de independizarlos pero a la vez de conseguir la comunicación entre ellos.

El museo va a quedar situado en el cuerpo más a la izquierda de los antes mencionados, en planta baja y con acceso independiente desde la calle, pero a su vez, desde él se puede llegar a las aulas y al teatro. Como dependencias anexas al museo se van a utilizar un patio existente en la parte posterior, y que se acondicionará para su utilización como museo al aire libre, y una pequeña habitación de reducidas dimensiones. En planta baja quedarán situados igualmente un distribuidor, con acceso independiente, un cuarto de calderas y en la parte más a la izquierda el teatro y las habitaciones anexas al mismo, escenario, vestuarios y aseos. El teatro también contará con una entrada independiente desde la calle. 


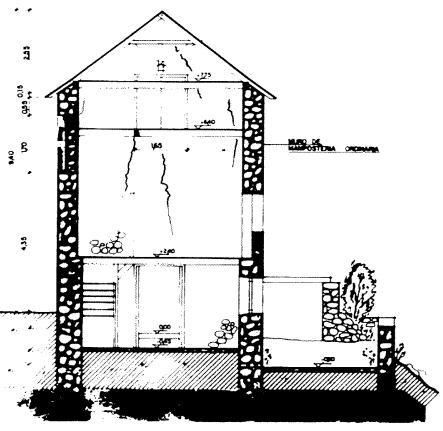

Sección 1-1'

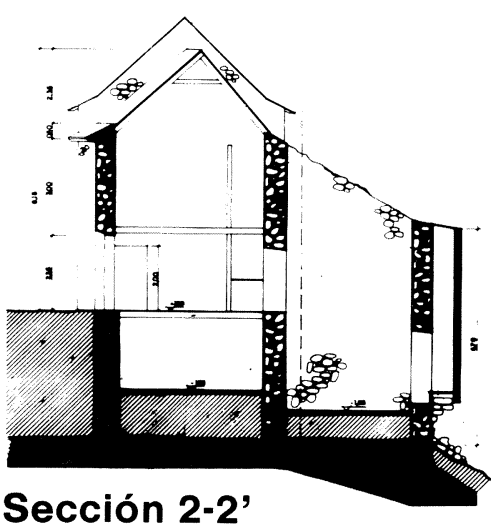

(3)
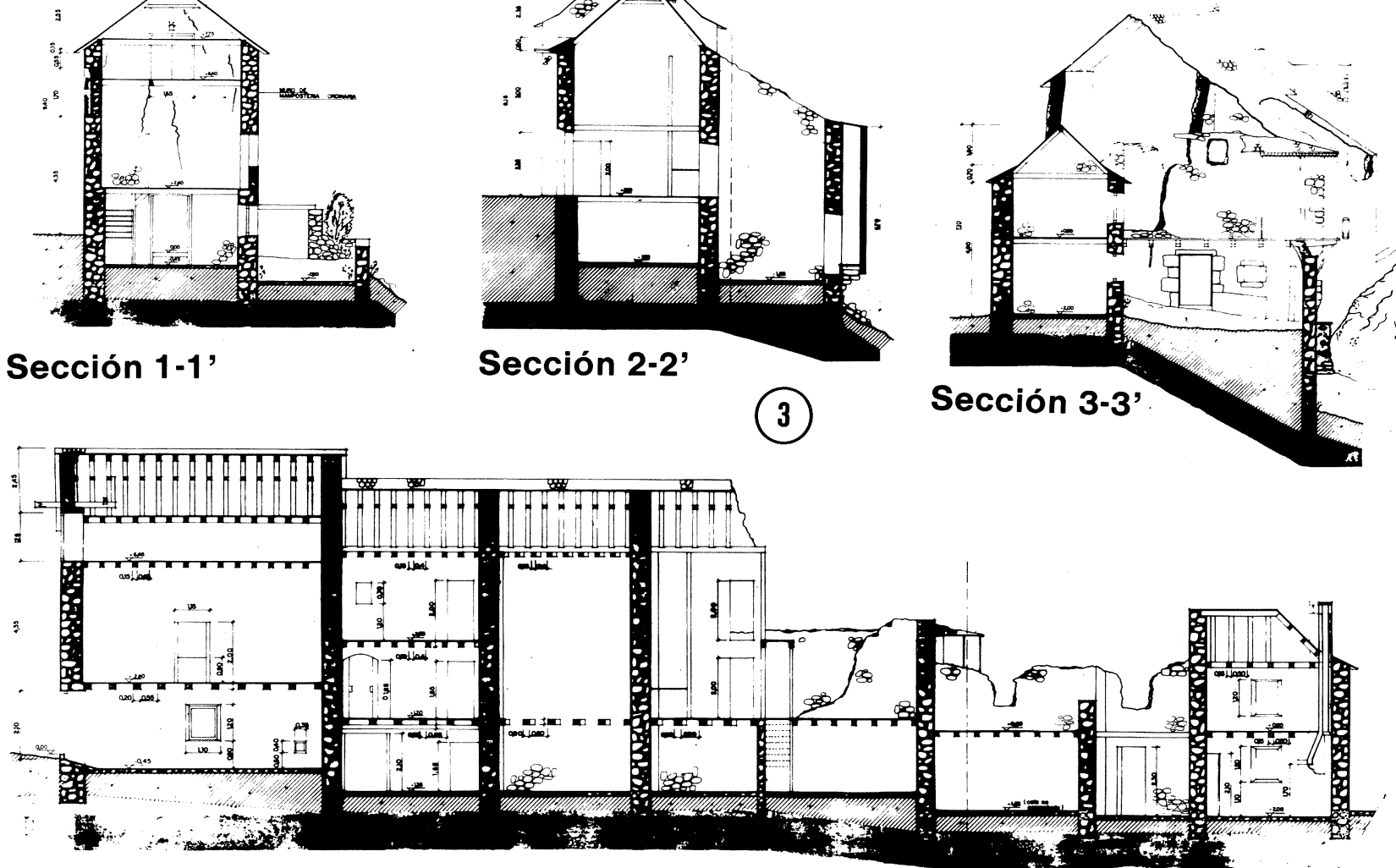

\section{Sección 4-4'}

\section{Planta baja}

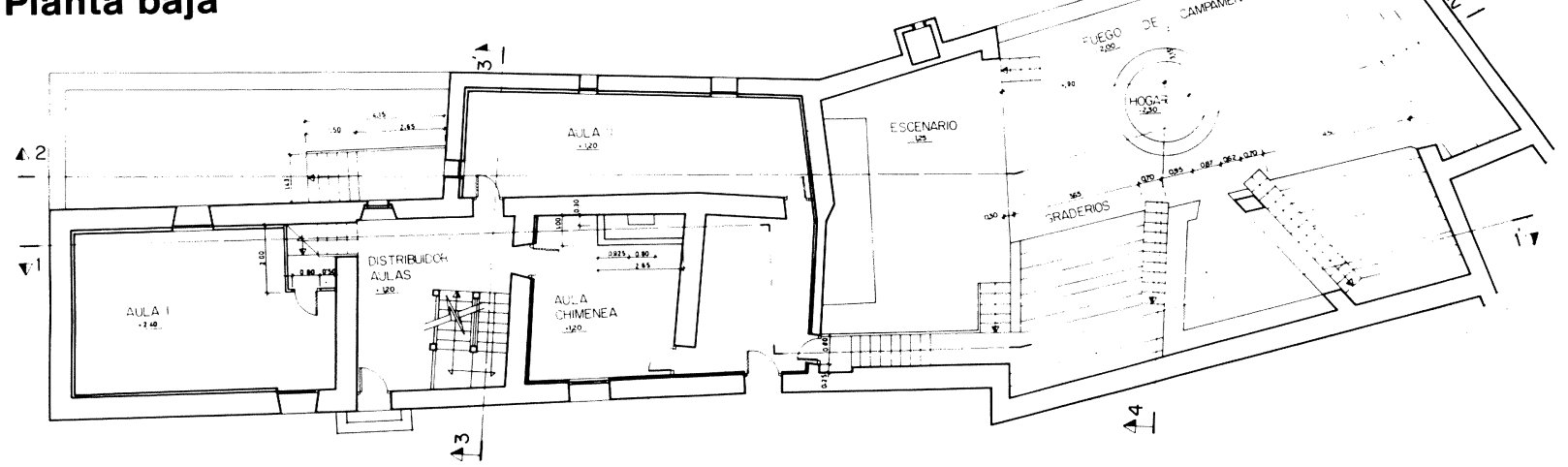

(4)

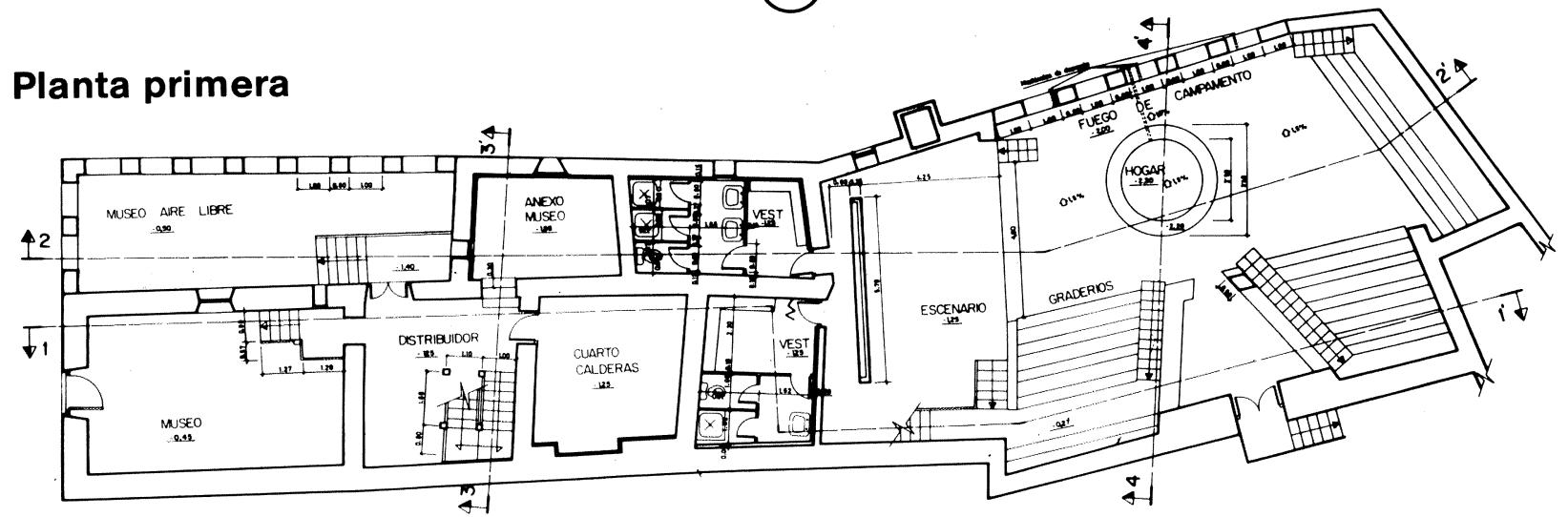


Tanto la planta primera como la alta, y siempre que las alturas lo permitan, se destinarán para aulas y aseos de las mismas. Este núcleo de aulas tiene acceso independiente desde la calle, pero a su vez desde él se puede acceder al museo y al teatro.

En la planta primera es de destacar el aula donde se situará una chimenea de nueva construcción, aunque respetando la tipologia de la zona y que puede tener una posible utilización como biblioteca, sala de reuniones o despacho. Esta chimenea se situará para así respetar la morfología con que contó el edificio en otra época.

La distribución completa de todo el edificio queda más claramente expuesta en el plano de secciones $n .^{\circ} 5$.

El desnivel existente entre los dos cuerpos antes mencionados y la exigencia de comunicación entre ambos, obliga a la construcción de un tramo de escalera por planta (ver sección 3-3, plano n. ${ }^{\circ}$ 7).

Observando el plano n. ${ }^{\circ} 6$ y comparándolo con el n.o 1 , se puede ver el criterio perseguido en todos los casos, de conservar y mantener la morfología anterior del edificio; así, y por ello, se mantiene el adosado aseo existente en la fachada posterior, se mantienen igualmente las dos lo- canas, no rompiéndose este criterio nada más que en dos casos: para la apertura de un hueco de acceso en la fachada principal, y la solución adoptada para el cerramiento del museo al aire libre y para el teatro, a lo que nos animó la vista que esta solución permite (ver plano n. ${ }^{\circ}$ ).

Las instalaciones son inexistentes en su totalidad, debiéndose proceder al diseño y cálculo de las mismas y siendo necesario su acometida desde las redes generales de distribución existentes en la plaza.

La instalación de fontanería comprende dotar de agua fría y caliente a los aseos y vestuarios situados en planta baja y a los aseos situados en la planta alta, en total se instalarán 3 duchas, 5 inodoros, 4 urinarios y 5 lavabos. Las tuberías serán de cobre.

En el cuarto de calderas quedará instalado un depósito acumulador de 5001 .

Para la red vertical de evacuación se emplearán bajantes de PVC; el desagüe de los aparatos se realizará en plomo colocándose los correspondientes botes sinfónicos $\mathrm{y}$, por último, para la red horizontal de evacuación se emplearán tuberias de fibrocemento situándose las correspondientes arquetas así como un pozo de resalto.
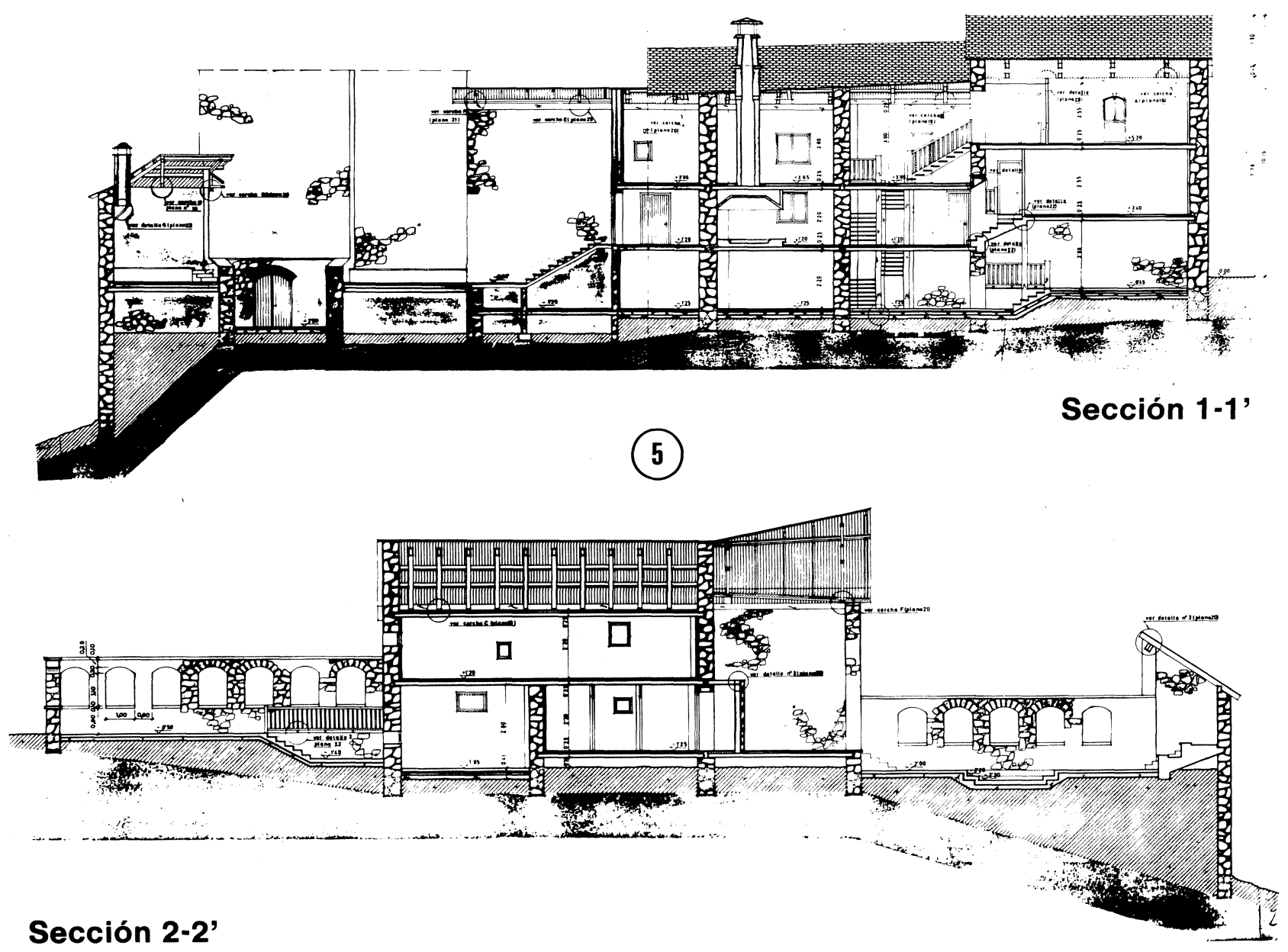


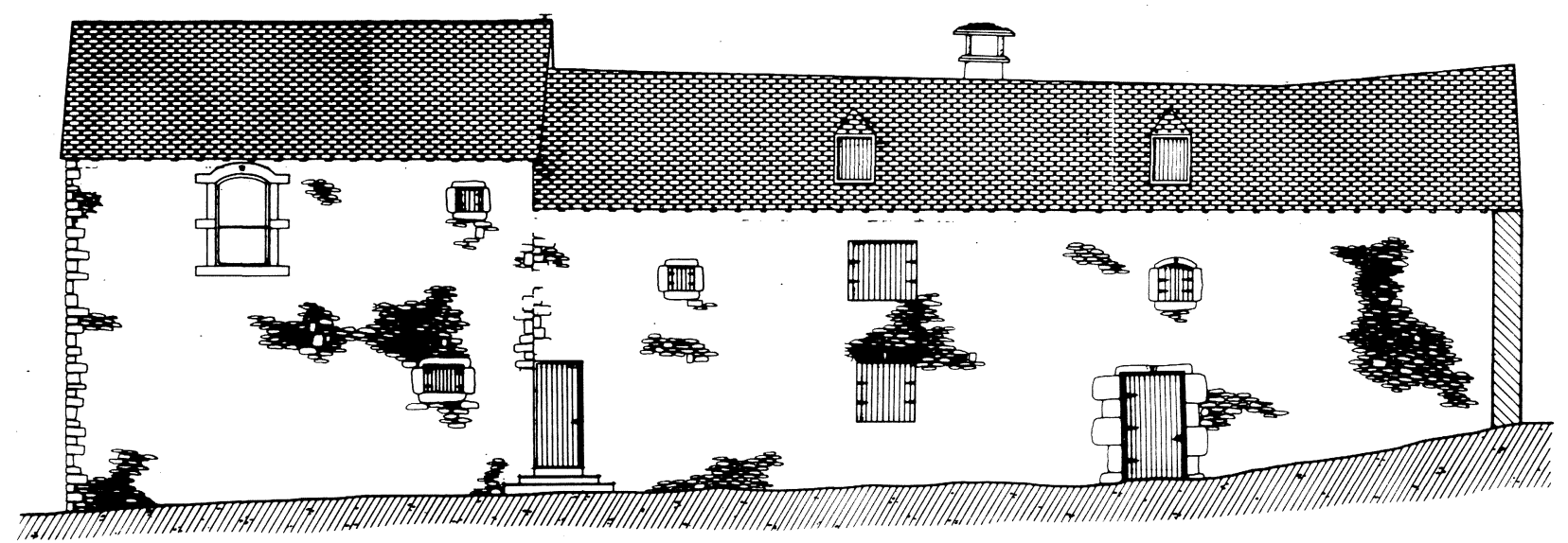

Alzado principal

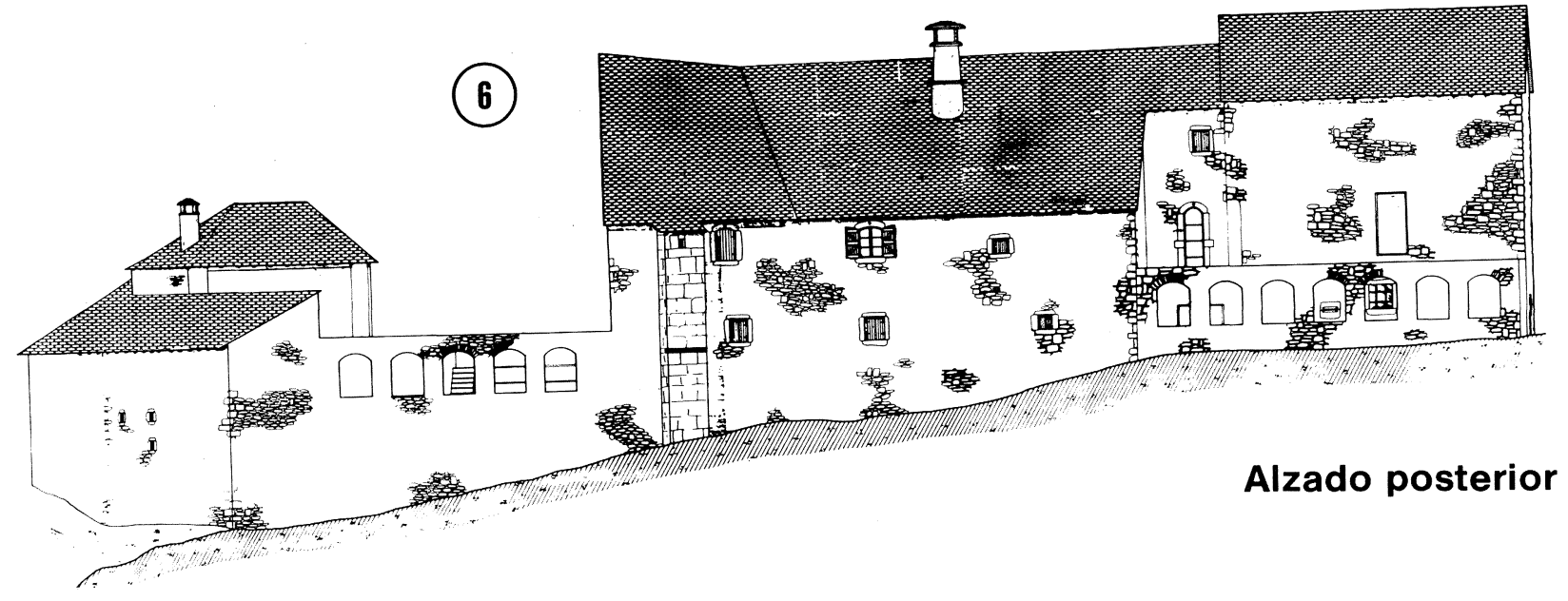

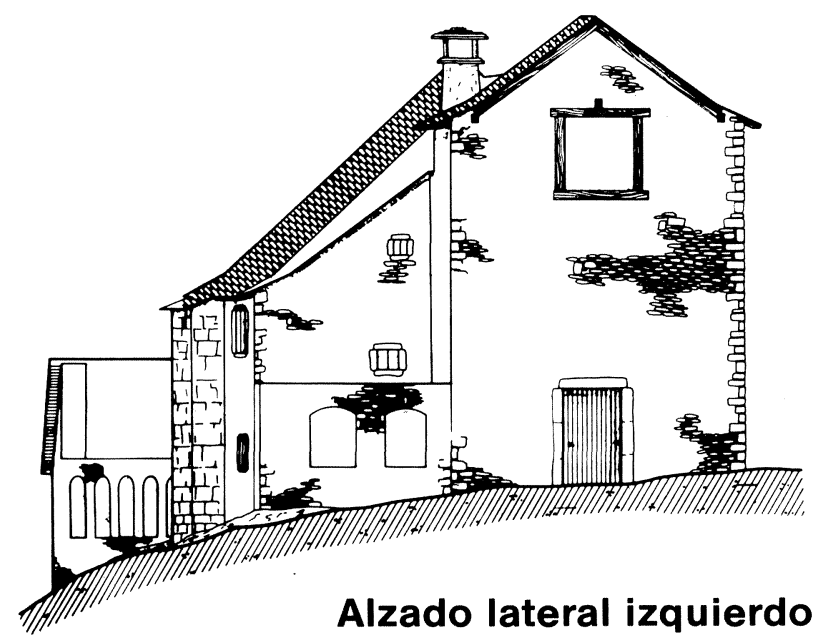

El sistema de calefacción será un sistema cerrado con distribución inferior, bitubular, circulación forzada, retorno directo y depósito de expansión cerrado. Los radiadores serán de hierro fundido. Las tuberias de distribución serán de cobre, empleándose una caldera con una potencia de $29.000 \mathrm{Kcal} / \mathrm{h}$. La instalación quedará dividida en tres circuitos. Se colocarán igualmente una bomba de 90
W y un depósito de 1811 de capacidad, todo ello convenientemente instalado en el cuarto de calderas.

El cálculo del coeficiente $\mathrm{k}_{\mathrm{g}}$ nos plantea el dilema de cumplir con la exigencia de la normativa, para lo cual deberiamos colocar, trasdosados en los paramentos de fachada, lo que suponía el no dejar vista la mampostería o no cumplir la normativa y mantener vistos los paramentos como se habia venido haciendo hasta el momento en las casas rehabilitadas. Nosotros, en parte optamos por la primera solución y colocamos trasdosado autoportante con placa Pladur-Term, salvo en el museo donde debido a su fin los paramentos quedarán vistos, además se emplearán en soleras, forjados y cubiertas los aislamientos necesarios en cada caso (ver detalles de aislamiento en planos n.o 10, 5 y 7).

En cuanto a la instalación eléctrica se ha tenido en cada caso en cuenta el uso y se han utilizado tanto lámparas incandescentes como fluorescentes.

El cálculo de la estructura se ha realizado conforme a la normativa vigente, adoptándose, en el caso de los forjados, como solución vigueta o doble vigueta de hormigón pretensado autoportantes o semirresistentes, bovedilla cerámica, mallazo de reparto y capa de compresión de 3 ó $5 \mathrm{~cm}$, según los casos (ver detalle forjado plano $\mathrm{n} .^{\circ} 7$ ). 


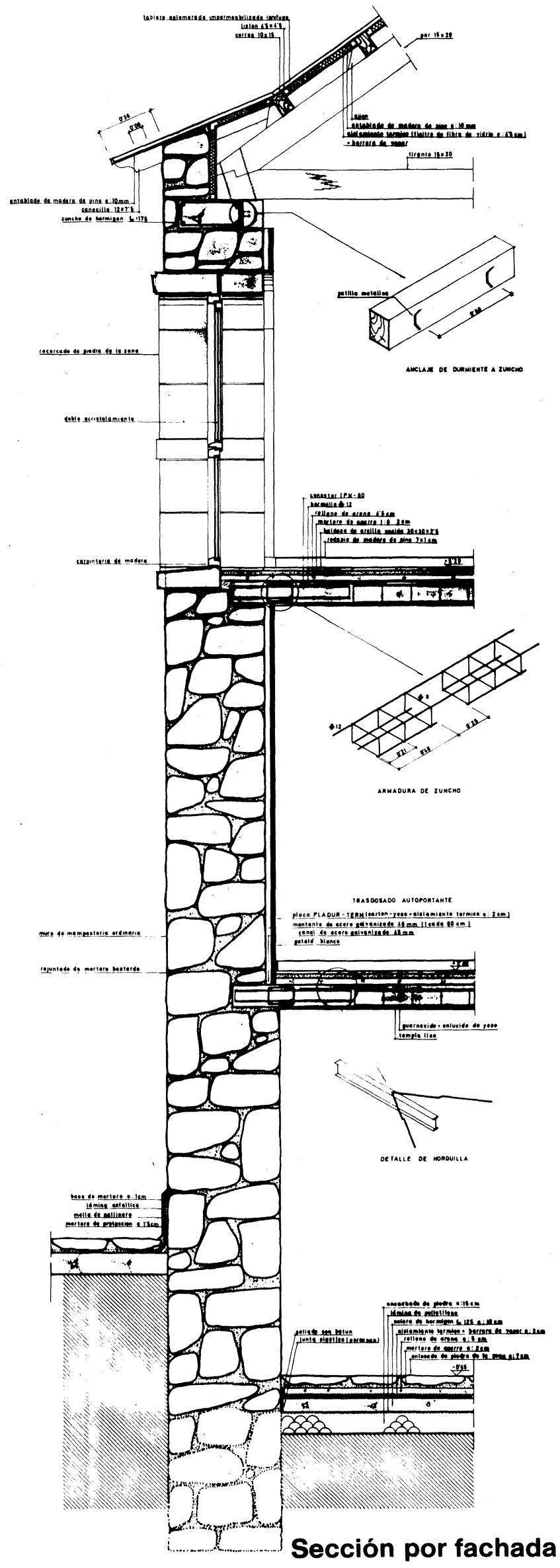

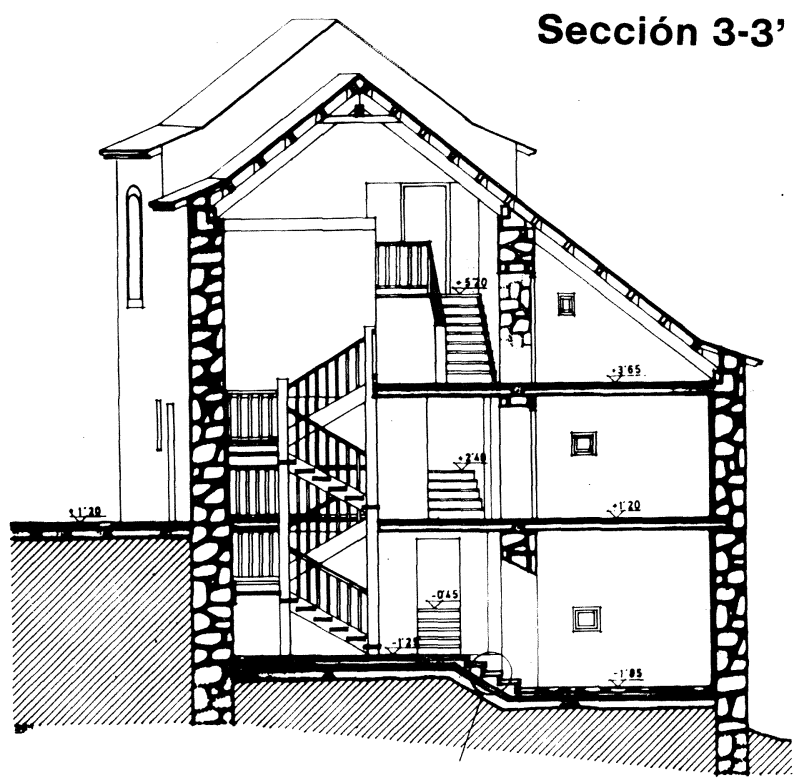

(7)

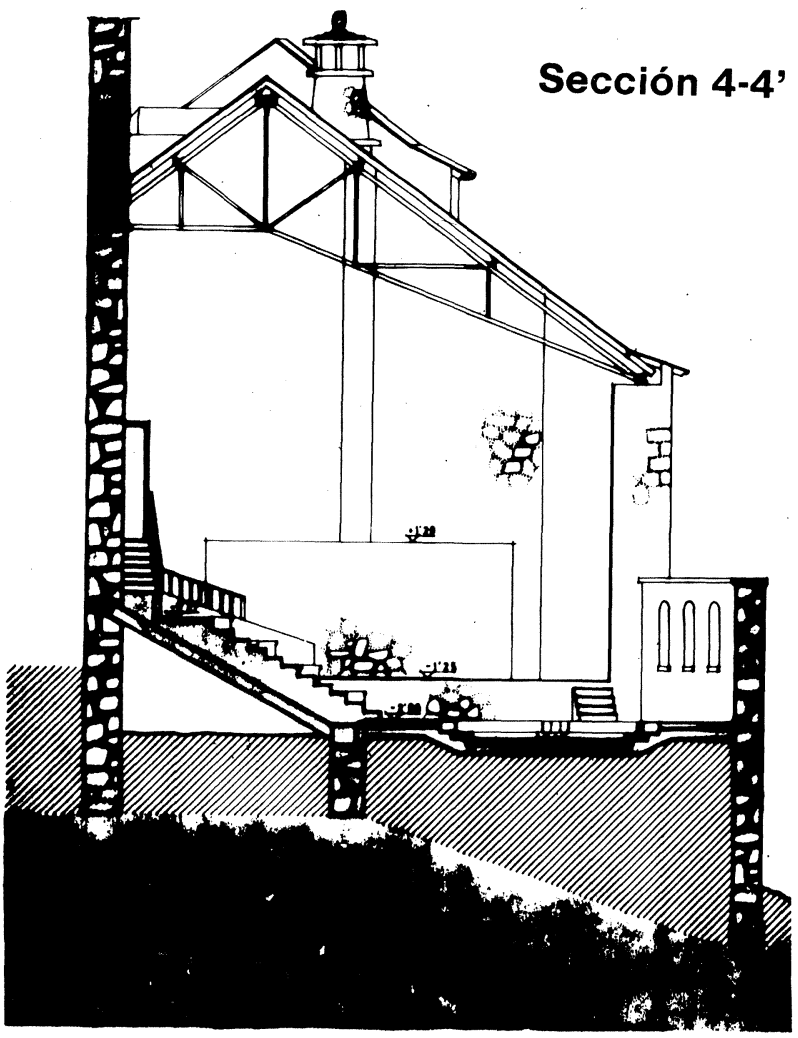

El sistema de cálculo empleado en forjados es el de estructura simplemente apoyada en sus dos extremos cuando no sean posibles zunchos de recibo en los muros o estructura apoyada en un extremo, y articulada en el otro cuando se trate de la coronación de un muro y sea posible un zuncho corrido. En el caso de las gradas se ha empleado un forjado inclinado de la misma forma antes 
mencionada, cuyo esquema de cálculo es el de estructura apoyada en un extremo y articulada en el otro: apoyada en el extremo superior debido a la imposibilidad de introducir un zuncho de recibo por tratarse de un muro medianero y articulada en el extremo inferior con un zuncho de coronación en muro. La formación de las gradas se realizará a base de bloques de hormigón y posterior revestimiento mediante piedra del lugar. El asiento será de piedra artificial.

La unión de los forjados con los muros se realizará a base de conectores formados por perfiles IPN con horquillas de conexión $\varnothing 12$, realizándose además un zuncho en el perímetro de forjado, convenientemente armado (ver sección fachada, plano n. ${ }^{\circ} 7$ ).

En los forjados se emplearán igualmente elementos metálicos; fundamentalmente se tratará de vigas $\mathrm{H}$ simplemente apoyadas; vigas IPN apoyadas en un extremo y articuladas en el otro, basándose este hecho en que el apoyo de la viga se hará articulado mediante soldadura de parte del alma y el apoyo se realizará sobre la mamposteria, soportes formados por 2 UPN en cajón y zancas de escalera a base de $\mathrm{H}$ o a base de UPN y posterior forjado de las mismas con rasillas. En cualquier caso las vigas quedarán siempre embebidas en el forjado.

De igual forma la estructura de cubierta se resolverá a base de estructura de madera y estructura metálica.

Para el cuerpo situado más a la izquierda se emplearán 4 cerchas tipo A (ver plano n. ${ }^{\circ}$ ), formadas por dos pares y un tirante. En este caso el esquema de cálculo es el de cercha apoyada en un extremo y articulada en el otro (ver detalles 1 y 3 , plano n. ${ }^{\circ} 8$, cercha tipo A). Los apoyos se harán mediante zuncho corrido de hormigón, existiendo un durmiente de madera que se utiliza como encofrado del propio zuncho. Los nudos de las cerchas se resolverán, como en el resto de los casos, mediante uniones antiguas, en el caso de los apoyos se empleará una doble espera (detalles 1 y 3 ) y en el caballete se colocará una hilera sobre un puentecillo (detalle 2), pieza que se empleará además para facilitar el montaje.

El apoyo simple se verificará mediante el apoyo de la cercha directamente sobre el hormigón, que deberá tener en estos puntos una terminación de gran finura.

La articulación se verificará mediante la colocación de una brida alrededor de la prolongación del tirante $y$ uniéndose ambos mediante pasadores metálicos. La brida quedará fijada al zuncho mediante soldadura a una placa de anclaje colocada anteriormente sobre el zuncho. Este apoyo articulado irá en muros distintos alternativamente para repartir sobre ambos muros los posibles empujes laterales originados por las cerchas.

En el distribuidor situado en el segundo cuerpo y ante la imposibilidad de colocar tirante, porque ello produciria cabezada, se emplearán dos cerchas tipo B (ver plano n. ${ }^{\circ}$ 8) de madera.
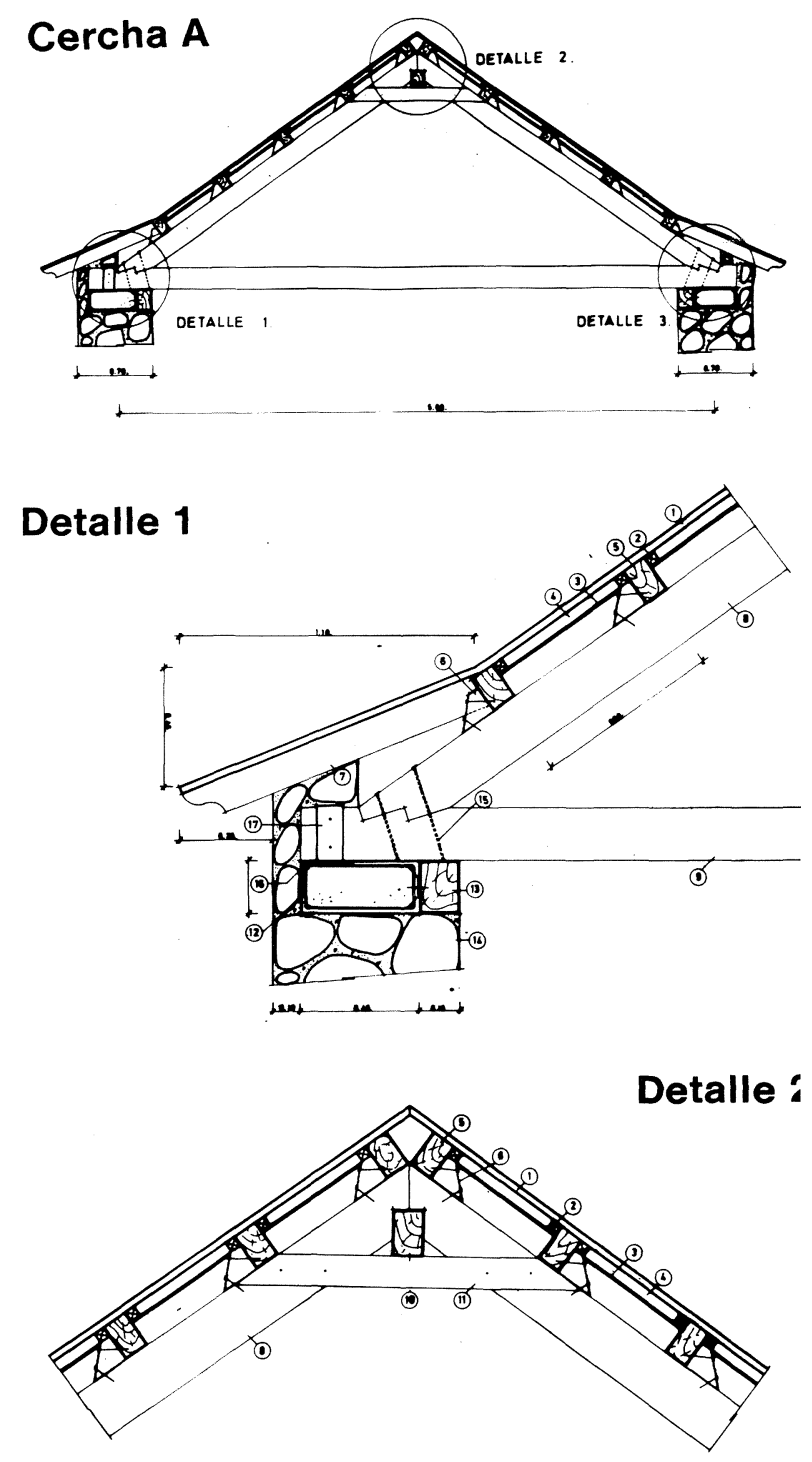

\section{Detalle 3}

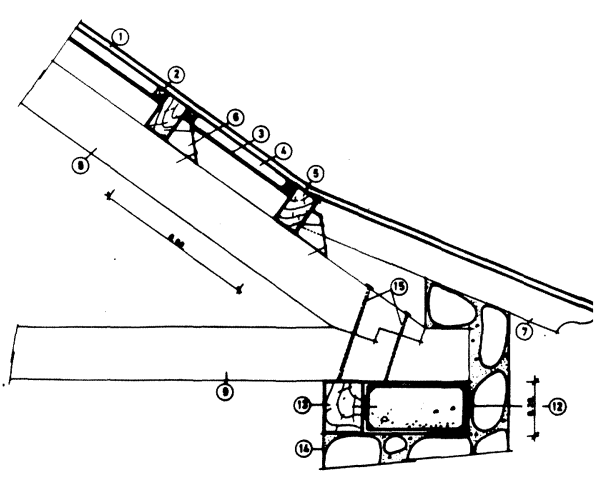

1.- Tablero aglomerado $30 \mathrm{~mm}$. 2.-Listón $45 \times 45 \mathrm{~mm}$. 3.-Entarima $10 \mathrm{~mm}$. 4.-Aislamiento IBR-aluminio. 5.-Correa $10 \times 15 \mathrm{~cm}$. 6. -St ción. 7.-Canete $7,5 \times 12,5 \mathrm{~cm}$. 8.-Par $15 \times 20 \mathrm{~cm}$. 9.-Tirante $15 \times$ cm. 10 - Hilera $125 \times 175 \mathrm{~cm}$ 11. Tabla de montaje $7,5 \times 125$ $\mathrm{cm}$. 10. Chich de mamposte 15.-Pasadores. 16.-Placa de apoyo $160 \times 200 \times 5 \mathrm{~mm}$. 17.-Pleti $5 \mathrm{~mm}$. 


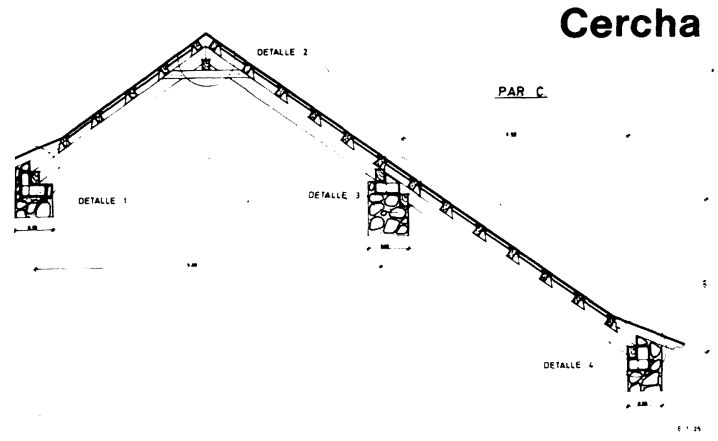

\section{Detalle 1}

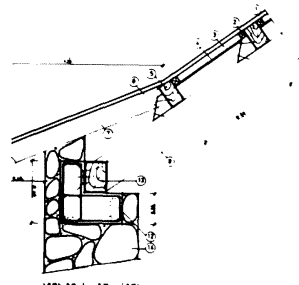

\section{Detalle 2}

(8)

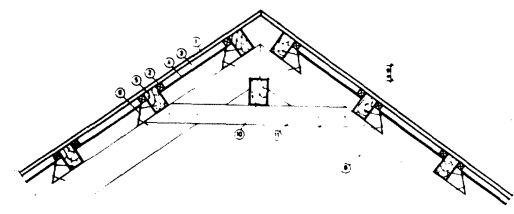

\section{Detalle 3}

\section{Detalle 4}

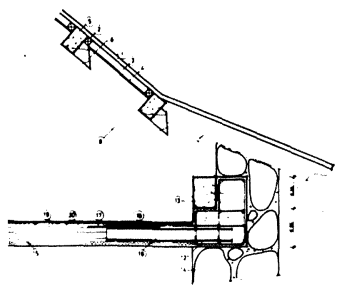

1.- Tablero aglomerado $30 \mathrm{~mm}$. 2.-Listón $45 \times 45 \mathrm{~mm}$. 3.-Aislamiento IBR-aluminio. 4.-Entarimado $10 \mathrm{~mm}$. 5.-Correa $10 \times 15 \mathrm{~cm}$. 6.-Ejión. 7.-Canete $7,5 \times 12,5 \mathrm{~cm}$. 8.-Par de $15 \times 20 \mathrm{~cm}$. 9.-Picadero $15 \times 20$ $\mathrm{mm}$. 10.-Hilera $12,5 \times 17,5 \mathrm{~cm}$. 11.-Tabla de montaje $7,5 \times 12,5 \mathrm{~cm}$. 12.-Zuncho. 13.-Durmiente $15 \times 20 \mathrm{~cm}$. 14.-Muro mampostería. 15.Vigueta semirresistente de hormigón pretensado. 16.-Conectador IPN80. 17. - Horquilla de conexión $\oslash$ 12. 18. - Armadura de refuerzo $\oslash 12$. 19.-M.E. $0,20 \times 0,20 \oslash 8,8$ AEH 400. 20.-Capa a compresión.

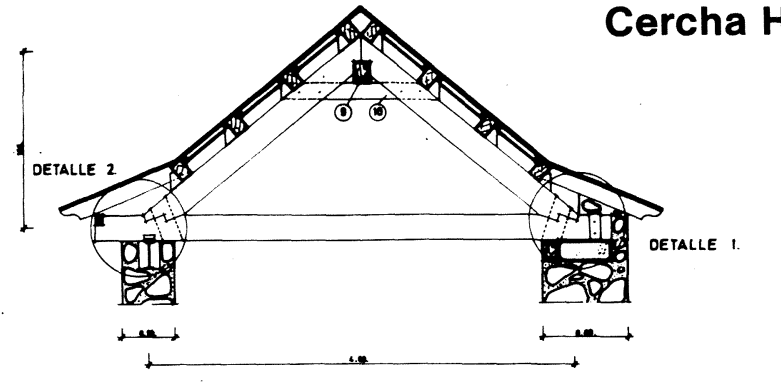

Detalle 1
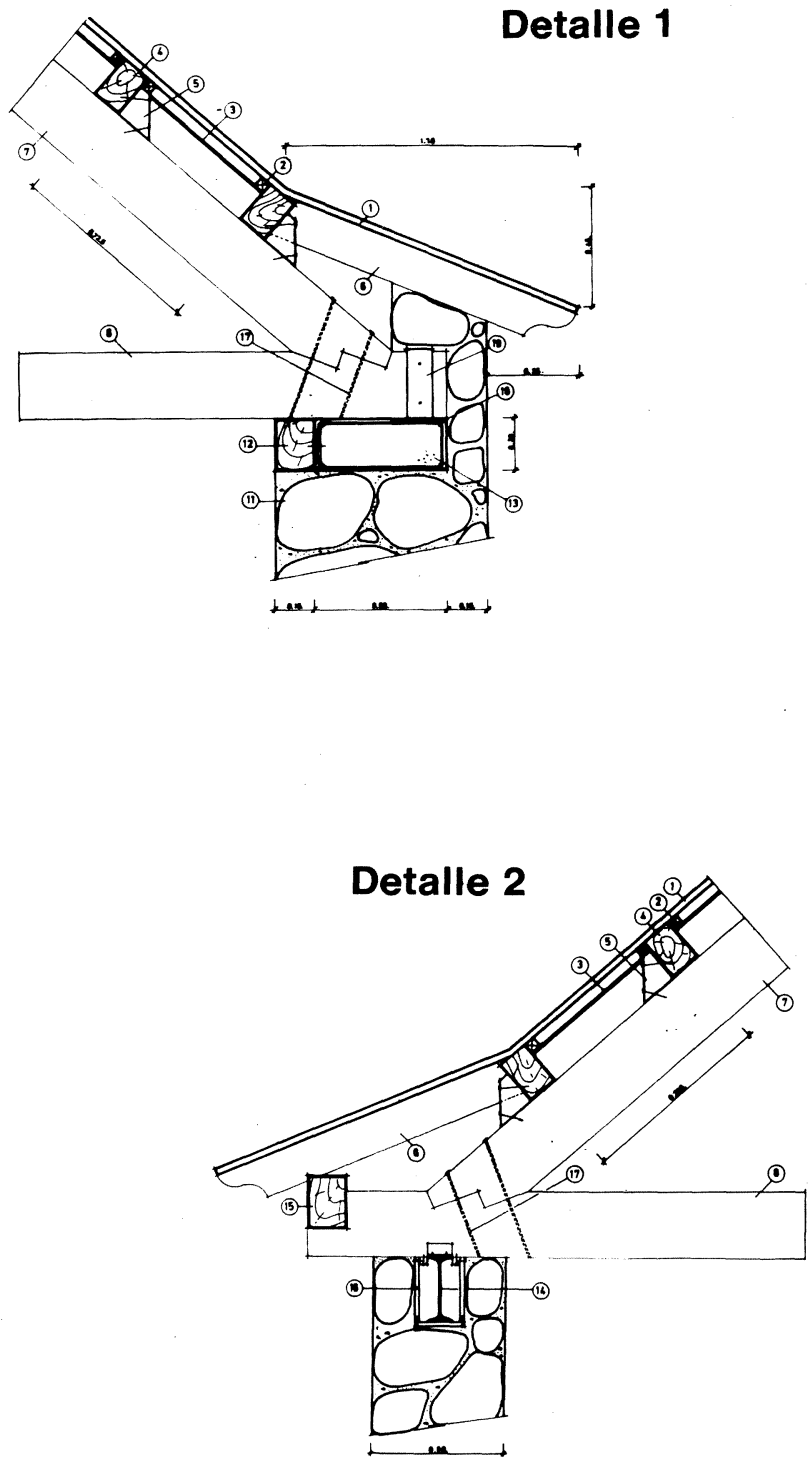

1.-Tablero aglomerado $30 \mathrm{~mm}$. 2.-Listón $45 \times 45 \mathrm{~mm}$. 3.-Entarimado $10 \mathrm{~mm}$. 4.-Correa $12,5 \times 17,5 \mathrm{~cm}$. 5.-Ejión. 6.-Canete 7,5 $\times 15 \mathrm{~cm}$. 7.Par $15 \times 25 \mathrm{~cm}$. 8. - Tirante $15 \times 25 \mathrm{~cm}$. 9.-Hilera $15 \times 20 \mathrm{~cm}$. 10.-Tabla de montaje $10 \times 15 \mathrm{~cm}$. 11.-Zuncho. 12.-Carrera $15 \times 20 \mathrm{~cm}$. 13.Muro de mampostería. 14. - Viga IPN-240. 15. -Viga madera $15 \times 20 \mathrm{~cm}$. 16.-Revestimiento de madera $185 \times 20 \mathrm{~mm} / 240 \times 20 \mathrm{~mm}$. 17.-Pasadores. 18. - Placa de apoyo $160 \times 200 \times 5 \mathrm{~mm}$. 19.-Pletina. 
En este caso el esquema de cálculo es el de arco de tres articulaciones, verificándose los apoyos articulados mediante embarbillado del par a un durmiente de madera situado sobre un zuncho de hormigón de forma trapezoidal (detalles 1 y 3 , plano n. ${ }^{\circ} 8$, cercha B).

En el resto del segundo cuerpo y no existiendo más problemas de cabezada, se volverán a emplear cerchas con tirante (ver plano n. ${ }^{\circ}$ ) tipo D. Los apoyos son semejantes a los de las cerchas tipo A.

Para la falsa situada en la parte posterior de este segundo cuerpo, la solución adoptada será la de disponer unos pares de madera tipo $\mathrm{C}$ (ver plano n.० 8), apoyados en el 8 , par tipo C). Esta articulación se realizará mediante embarbillado del par al durmiente de madera que nos transmite la carga al zuncho de coronación, donde a su vez queda embebido el forjado de piso que actúa como tirante absorbiendo los posibles empujes laterales que pueda originar la cubierta.

La cubierta de las gradas laterales se realizará a base de una cercha de madera, tipo $\mathrm{H}$ (ver plano n. ${ }^{\circ} 8$ ) y otra metálica, tipo $\mathrm{G}$, de la que luego hablaremos.

El esquema de cálculo de la cercha $\mathrm{H}$ es el de estructura apoyada en un extremo sobre una viga IPN (detalle 2, cercha $\mathrm{H}$, plano $n .{ }^{\circ} 8$ ) y articulada en el otro mediante doble embarbillado sobre el durmiente de madera (detalle 2, cercha $\mathrm{H}$, plano n. ${ }^{\circ} 8$ ).

La estructura de cubierta de las gradas de fondo se resolverá a base de pares de madera, tipo I (ver plano n. ${ }^{\circ} 9$ ), articulados en su extremo inferior sobre zuncho corrido de hormigón en coronación de muro (detalle 1, par I, plano 9), y apoyado en su extremo superior sobre viga metálica (detalle 2, par I, plano n.o 9). Esto se justifica ya que la luz de la viga metálica es muy grande y al trabajar a flexión desviada necesitaríamos una viga armada, con lo cual hemos optado por la solución de hacerla trabajar a flexión simple, absorbiendo los empujes de la cubierta el muro de mampostería.

En todos estos casos, sobre las cerchas de madera se dispondrán correas formadas por piezas rectangulares, también de madera. El apoyo de la correa se realizará directamente sobre la cercha auxiliándonos para la transmisión de la carga y la unión con la cercha de ejiones de madera.

La unión de los canetes con la correa situada en el quiebro del ensillado se realizará mediante angulares atornillados a ambas piezas (ver detalle plano n.o 9).

\section{Cubierta grada (par}
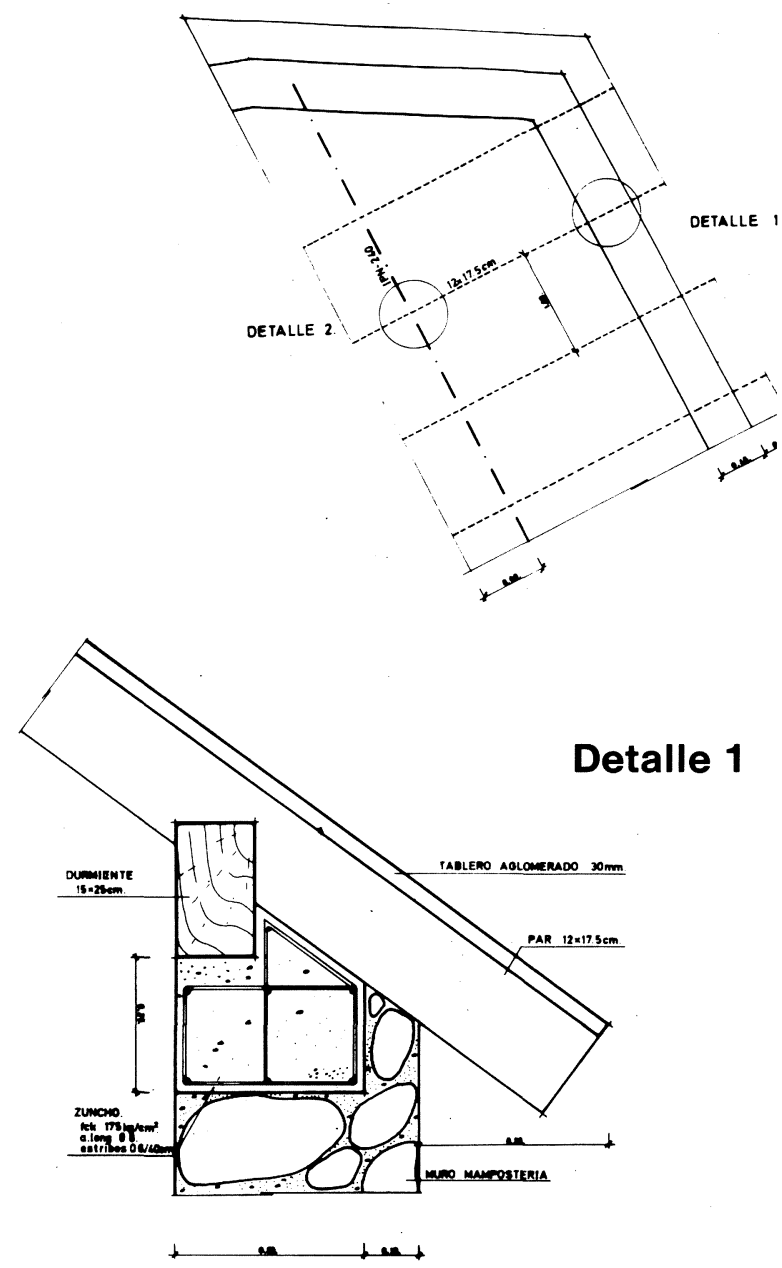

\section{Detalle 2}

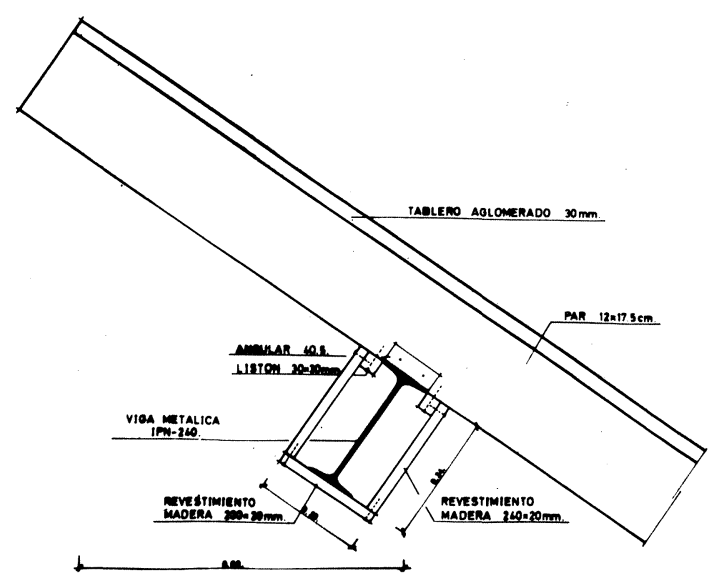




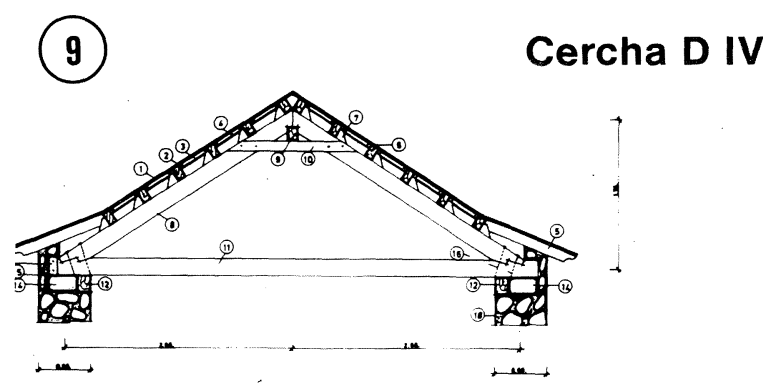

ətalle 1

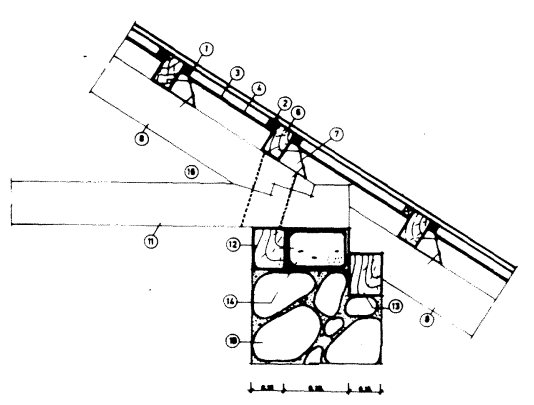

\section{nión canete}

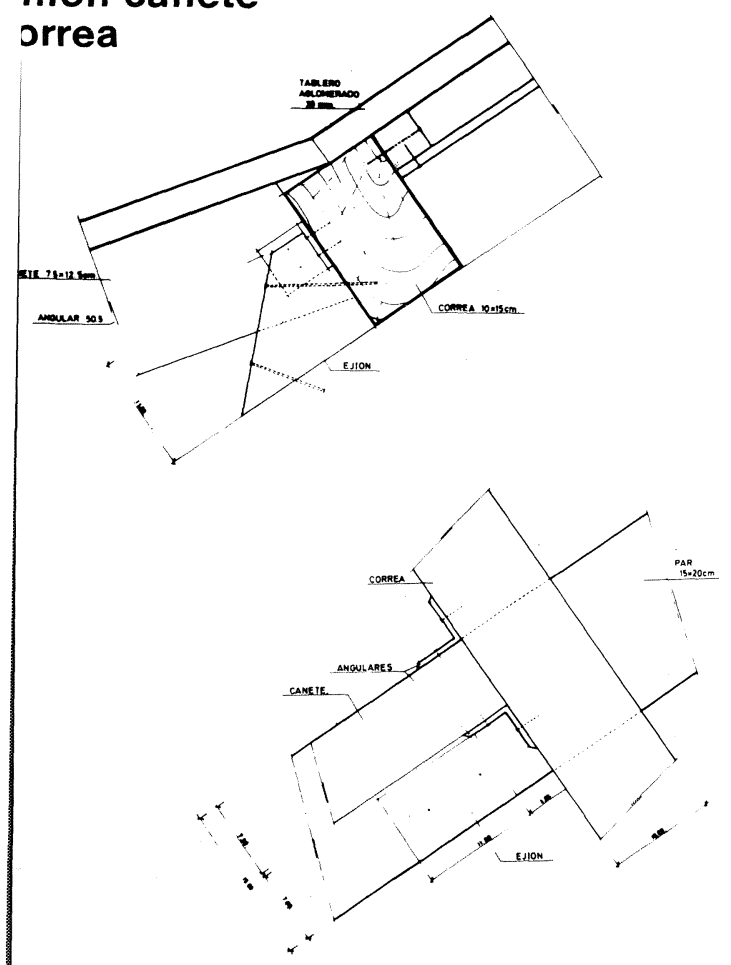

- Tablero aglomerado $30 \mathrm{~mm}$. 2.-Listón. 3.-Aislamiento IBR-aluminio. - Entarimado. 5.-Canete 7,5 X12,5 cm. 6.-Correa $10 \times 15 \mathrm{~cm}$. 7.ión. 8. - Par $15 \times 20 \mathrm{~cm}$. 9. - Hilera $12,5 \times 17,5 \mathrm{~cm}$. 10.-Tabla de monje $7,5 \times 12,5 \mathrm{~cm}$. 11. - Tirante $15 \times 20 \mathrm{~cm}$. 12.-Durmiente $15 \times 20 \mathrm{~cm}$. B.-Picadero $15 \times 20 \mathrm{~cm}$. 14.-Zuncho. 15. - Placa de apoyo $160 \times 200 \times 5$

m. 17.-Pasadores. 17.-Pletina $5 \mathrm{~mm}$. 18.-Muro de mampostería.
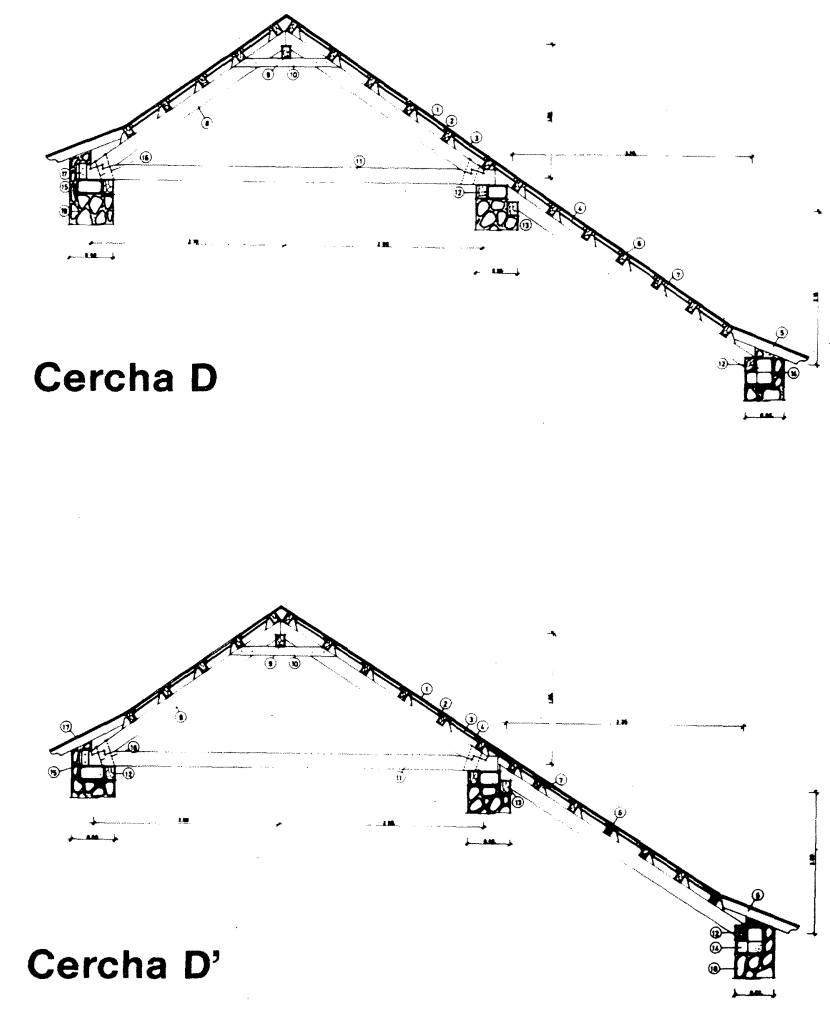

\section{Cercha D'”}

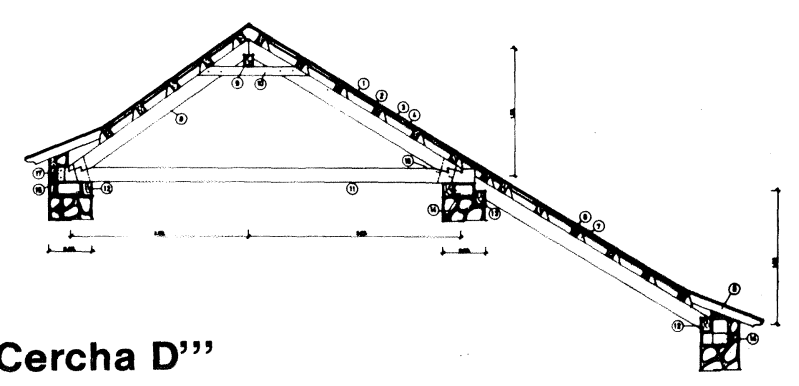




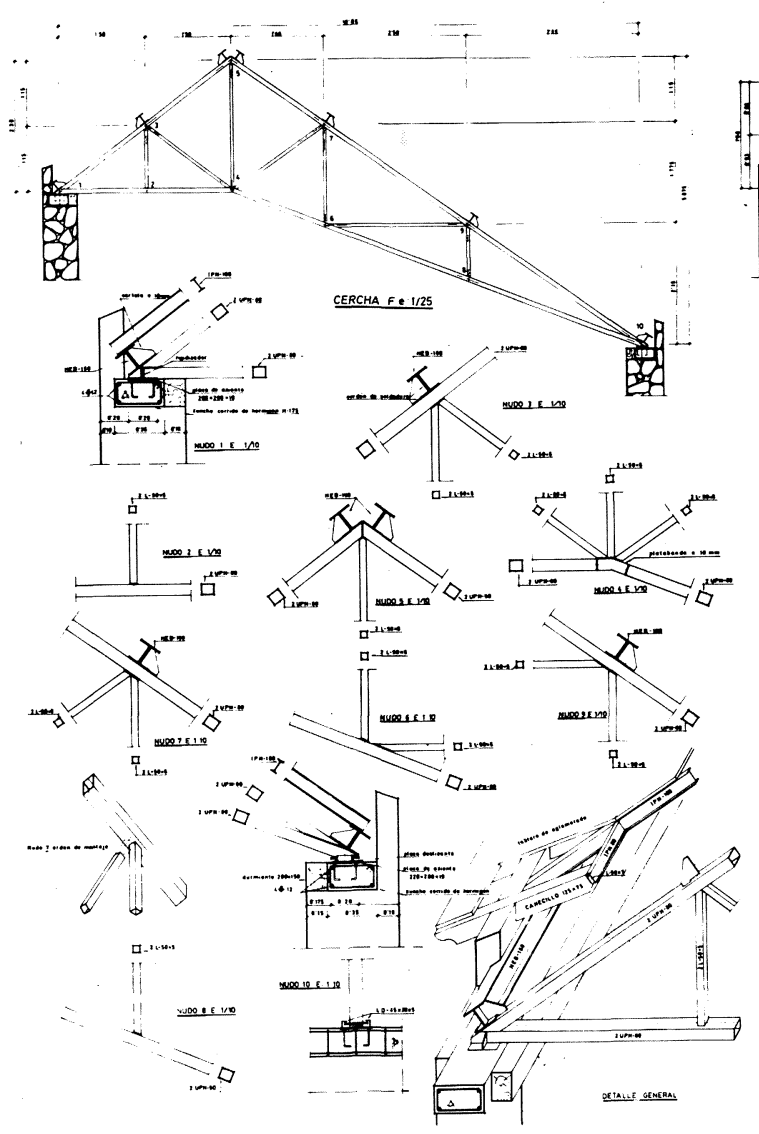

Detalles estructura

Sobre las correas se dispondrán tableros de aglomerado convenientemente tratados, clavados, colocados siguiendo la dirección de la máxima pendiente y con juntas alternadas.

Para el escenario se adoptarán dos cerchas metálicas (tipos E y F) apoyadas sobre zunchos corridos de hormigón (plano n.o 10).

Sobre los nudos de las mismas descansan correas metálicas que nos transmiten las cargas de unos parecillos que a su vez recogen la del tablero de aglomerado que forman los faldones. Esto se ha realizado así porque situando las correas en los nudos de las cerchas, las distancias entre ellas eran importantes y excesivas para las admitidas por el tablero de aglomerado por lo que había que situar otro elemento que son los parecillos.

Las cerchas están constituidas por tubos formados por UPN en pares y tirantes y L en las piezas interiores. La soldadura entre los distintos elementos se realiza en ángulo, de forma que las piezas traccionadas vayan pisadas por las comprimidas.

El esquema de cálculo empleado es el de cercha apoyada en un extremo y articulada en el otro, esto es debido a que la cercha no es simétrica de forma, pudiendo originar desplazamientos que si son coaccionados darán lugar a empujes, lo que seria contraproducente.
El apoyo articulado se realizará mediante soldadura del tirante a una placa de anclaje colocada a tal fin en el zuncho.

El apoyo deslizante se realizará mediante una placa circular fijada previamente al zuncho de hormigón sobre la que deslizará la cercha, colocándose unos angulares para evitar el levantamiento de la misma. Las correas apoyan directamente sobre la cercha, verificándose la unión entre ambas mediante cartelas metálicas. Los parecillos se soldarán directamente a las correas. El tablero irá cogido a los parecillos mediante tuerca cuya cabeza irá provista de arandela y ambos introducidos en un cajeado realizado previamente en el tablero a tal efecto.

En las gradas laterales, y como ya dijimos antes, se empleará una cercha metálica tipo G (ver plano 10). Su esquema de cálculo es el de cercha apoyada en un extremo y articulada en el otro. El apoyo articulado se realizará en el muro de mamposteria mediante soldadura del tirante a una ménsula metálica introducida en el muro. El apoyo simple se realizará sobre la placa de coronación del soporte metálico y auxiliándose con angulares (detalles plano n..$^{\circ} 10$, cercha $G$ ). En este caso las correas que serán de madera se unirán a la cercha mediante doble cartela y placa atornillada a la correa.

Fuera ya del capítulo de cubiertas, pero dentro aún de la estructura, es de destacar la escalera de acceso al teatro, formada a base de zancas metálicas tipo HEB. 
Una vez estudiado el volumen y complejidad de la obra a ejecutar, y en base a unos recursos y medios en función de las disponibilidades del lugar, se llegó a la conclusión de que el plazo óptimo de ejecución es de 225 días laborables. Creemos que éste es el plazo más razonable para un coste de ejecución asimismo razonable.
Hemos estimado después del estudio pertinente un presupuesto de contrata de $28.361 .753,00$ ptas.

El estudio, asimismo, también ha comprendido un estudio de seguridad con las normas a exigir en cada caso en función del tajo a ejecutar y las características del mismo.

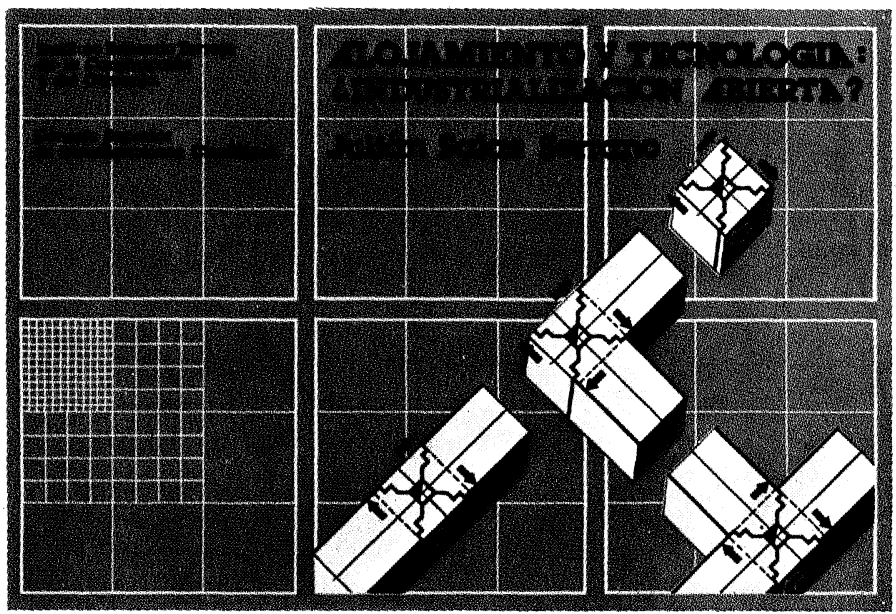

\section{ALOJAMIENTO Y TECNOLOGIA:} ¿INDUSTRIALIZACION ABIERTA?

JULIAN SALAS, ING. IND. (I.E.T.c.c.)

Un volumen de 160 páginas, 109 figuras y 16 tablas. Tamaño $240 \times 168 \mathrm{~mm}$. Encuadernado en rústica. Precios: España, 1.200 ptas; extranjero, 17 \$ USA.

\section{SUMARIO:}

Prólogo Prof. G. Ciribini.

\section{Introducción}

Capítuio 1.- La industrialización en las proclamas y manifiestos de arquitectura.

Capitulo 2.-¿Réquiem por la construcción industrializada?

Capitulo 3. - Algunos conceptos básicos.

Capítulo 4.-¿Proyecto tradicional, construcción industrializada?

Capitulo 5.-Componentes.

Capitulo 6. - La coordinación dimensional hoy.

Capitulo 7.-Flexibilidad, intercambiabilidad y catálogos.

Capítulo 8. - Industrialización, normativa y calidad.

Capitulo 9.-Reflexiones finales.

publicación del

INSTITUTO EDUARDO TORROJA 